\title{
Decadal Variation in Raindrop Size Distributions in Busan, Korea
}

\author{
Cheol-Hwan You ${ }^{1}$ and Dong-In Lee ${ }^{2}$ \\ ${ }^{1}$ Atmospheric Environmental Research Institute, Pukyong National University, Yongso-ro, Nam-gu, \\ Busan 608-737, Republic of Korea \\ ${ }^{2}$ Department of Environmental Atmospheric Sciences, Pukyong National University, Yongso-ro, Nam-gu, \\ Busan 608-737, Republic of Korea \\ Correspondence should be addressed to Dong-In Lee; leedi@pknu.ac.kr
}

Received 18 November 2014; Revised 12 March 2015; Accepted 25 March 2015

Academic Editor: Monique Leclerc

Copyright @ 2015 C.-H. You and D.-I. Lee. This is an open access article distributed under the Creative Commons Attribution License, which permits unrestricted use, distribution, and reproduction in any medium, provided the original work is properly cited.

\begin{abstract}
This paper investigated the variability of raindrop size distributions (DSDs) in Busan, Korea, using data from two different disdrometers: a precipitation occurrence sensor system (POSS) and a particle size velocity (Parsivel) optical disdrometer. DSDs were simulated using a gamma model to assess the intercomparability of these two techniques. Annual rainfall amount was higher in 2012 than in 2002, as were the annually averaged $D_{m}$ (which was $0.1 \mathrm{~mm}$ greater in 2012) and the frequency of convective rain. Severe rainfall (greater than $20 \mathrm{~mm} \mathrm{~h}^{-1}$ ) occurred more frequently and with a larger $D_{m}$ in 2012. The values of $D_{m}$ from July, August, and December, 2012, were much greater than from other months when compared with 2002. Larger raindrops contributed to the higher rain rates that were observed in the morning during 2012, whereas relatively smaller raindrops dominated in the afternoon. These results suggest that the increase in raindrop size that has been observed in Busan may continue in the future; however, more research will be required if we are to fully understand this phenomenon. Rainfall variables are highly dependent on drop size and so should be recalculated using the newest DSDs to allow more accurate polarimetric radar rainfall estimation.
\end{abstract}

\section{Introduction}

Drop size distributions (DSDs) provide important information for the microphysical structure of precipitation and describe the statistical distribution of falling raindrops' size and number concentration. Also DSDs play an important role in the remote sensing of rainfall and the behavior of electromagnetic waves in the atmosphere $[1,2]$. Measurements of DSDs have been used extensively to calculate both radar reflectivity and the rate of rainfall from conventional radar data, but no single reflectivity-rainfall (Z-R) relationship can be used across the world because DSDs can vary both between storms and within an individual storm $[3,4]$.

The earliest disdrometers that were developed to measure DSDs used ground-based measurements that relied on the flour method [5] and the filter paper method [6]. Subsequently, other techniques were developed, including the impact-type disdrometer [7], the radar-type disdrometer [8], the laser-optical-type disdrometer [9], and the advanced 2D video disdrometer (2DVD) [10]. The particle size velocity (Parsivel) optical disdrometer is a low cost, durable, and reliable instrument, making it well suited to deployment into networks for the study of small-scale variability in DSDs [11]. The POSS (precipitation occurrence sensor system) is a small Doppler radar and is more sensitive to wind effects than other disdrometers $[12,13]$. Several studies have compared the various disdrometers; for example, in experimental research, the 2DVD produced better matches gages than the JossWaldvogel [14] and the Parsivel disdrometers $[15,16]$. Krajewski et al. [17] showed that the Parsivel measures greater numbers of small drops ( 0.2 to $0.4 \mathrm{~mm}$ ) than the 2DVD and generally reports higher rainfall rates. Thurai et al. [15] found that the Parsivel records higher mass-weighted mean diameters and rainfall rates than the 2DVD, and this was most prominent when the rain rate was greater than $30 \mathrm{~mm} \mathrm{~h}^{-1}$. However, they also noted that this is dependent on climatology. There have been several studies in Korea focusing on 
the characteristics of DSDs [18], Z-R relationship calculations [19], and polarimetric applications [20, 21] using the POSS.

Much effort has been directed towards the modeling of DSDs based on observations of real DSDs. Initially, Laws and Parsons [5] proposed that DSDs were best described by an exponential distribution and then Marshall and Palmer [6] suggested fixed values for the intercept of $8000 \mathrm{~mm}^{-1} \mathrm{~m}^{-3}$ and the slope-rainfall rate relationship. Subsequently, the gamma model was introduced to better depict natural DSDs [22] using three parameters: the intercept, shape, and slope. Normalization was introduced into the model by Willis [23] and adapted by Testud et al. [24] and Illingworth and Blackman $[25,26]$ to explain the physical description of DSD parameters with respect to the gamma model.

As variability in DSDs is dependent on climatological conditions and geographical location [27], many observational studies have taken place in a variety of climatic locations such as in midlatitude [28, 29], maritime [30], continental [31], tropical [32-34], and equatorial environments [35]. However, there have been few studies of the climatological variation of DSDs at one location using observed disdrometer data.

This paper uses POSS and Parsivel data to quantify the changes in DSDs that occurred between 2002 and 2012 in Busan, Korea. In Section 2, POSS and Parsivel datasets, quality control, and gamma model simulations using different drop-size channels are described. Section 3 discussed the yearly and monthly variation in DSDs followed by a discussion of diurnal variations. Finally, we provide concluding remarks and a summary of our results in Section 4.

\section{Data and Methodology}

2.1. Disdrometers and Data Processing. The POSS is a lowpower X-band bistatic system radar capable of measuring 34 channels from 0.34 to $5.34 \mathrm{~mm}$ (a more detailed description is provided by Sheppard and Joe [12]). The Parsivel disdrometer is a laser-optic system that measures 32 channels from 0.062 to $24.5 \mathrm{~mm}$ (detailed specifications are described by LöfflerMang and Joss [9]). One-minute DSDs were obtained from POSS for 2002 and from Parsivel for 2012, excluding wintertime and rainfall events caused by typhoons. Unreliable data, defined as belonging to the following categories, were removed: 1 -min rain rate less than $0.1 \mathrm{~mm} \mathrm{~h}^{-1}$; total number concentrations of all channels less than 10; drop numbers counted only in the lower 10 channels $(0.84 \mathrm{~mm}$ for POSS and $1.187 \mathrm{~mm}$ for Parsivel); and drop numbers counted only in lower 5 channels $(0.54 \mathrm{~mm}$ for POSS and $0.562 \mathrm{~mm}$ for Parsivel). The data were also removed if the difference in the amount of rainfall measured between disdrometers and gage was greater than $50 \%$. The DSD data analyzed in this study comprised 26,427 and 16,591 samples in 2002 and 2012, respectively.

2.2. Normalized Gamma Distribution. The normalized gamma distribution was used in this study because its parameters provide the physical meaning for DSDs [24, 26, 29]. The

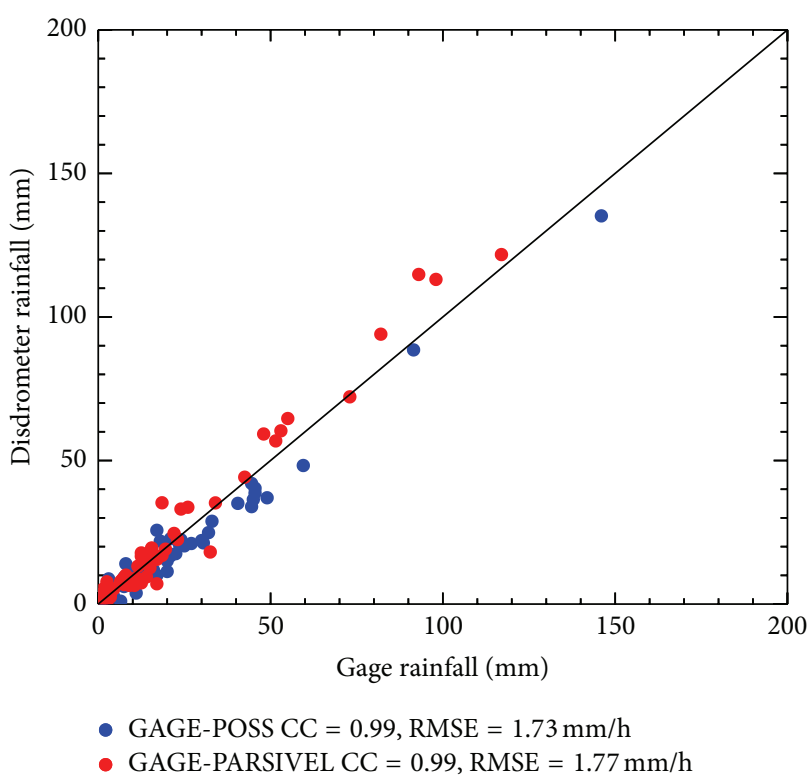

FIGURE 1: Scatter plots of daily rainfall from disdrometers and gages in 2002 and 2012. Blue circles indicate the gage-POSS relationship and red circles the gage-Parsivel relationship.

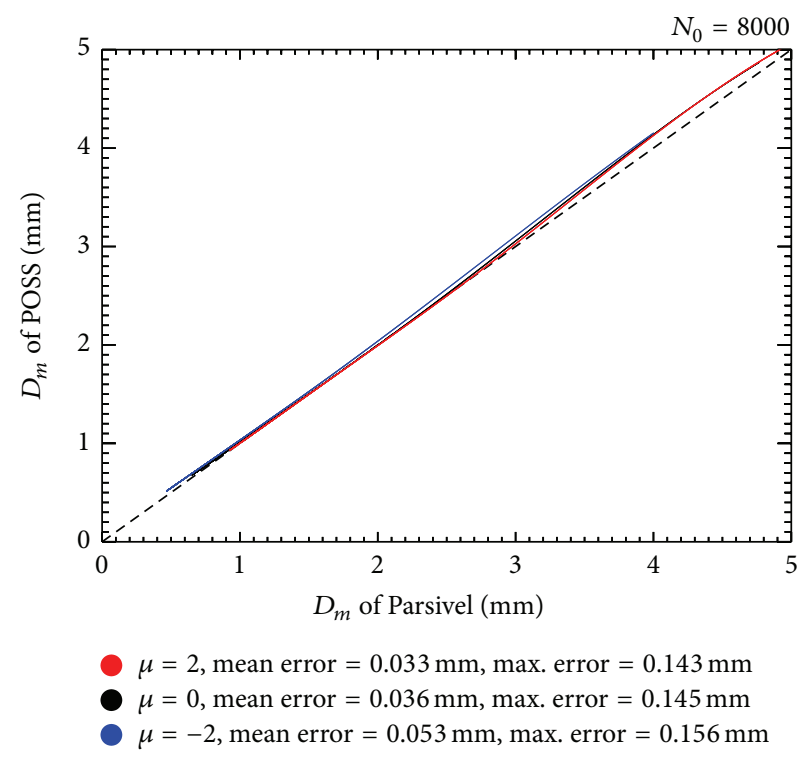

FIgURE 2: Comparisons between the $D_{m}$ calculated from DSDs simulated by the gamma model using the same channels as the Parsivel and the POSS system. The red, black, and blue solid line shows the difference between Parsivel and POSS with different shapes, 2,0 , and -2 , respectively.

mass-weighted mean diameter $\left(D_{m}\right)$ can be calculated as the ratio between the fourth and third moments of the DSD:

$$
D_{m}=\frac{\int_{0}^{D_{\max }} D^{4} N(D) d D}{\int_{0}^{D_{\max }} D^{3} N(D) d D} .
$$

The rainwater content $(W)$ is calculated as

$$
W=\frac{\pi}{6} \rho_{w} \int_{0}^{D_{\max }} D^{3} N(D) d D,
$$




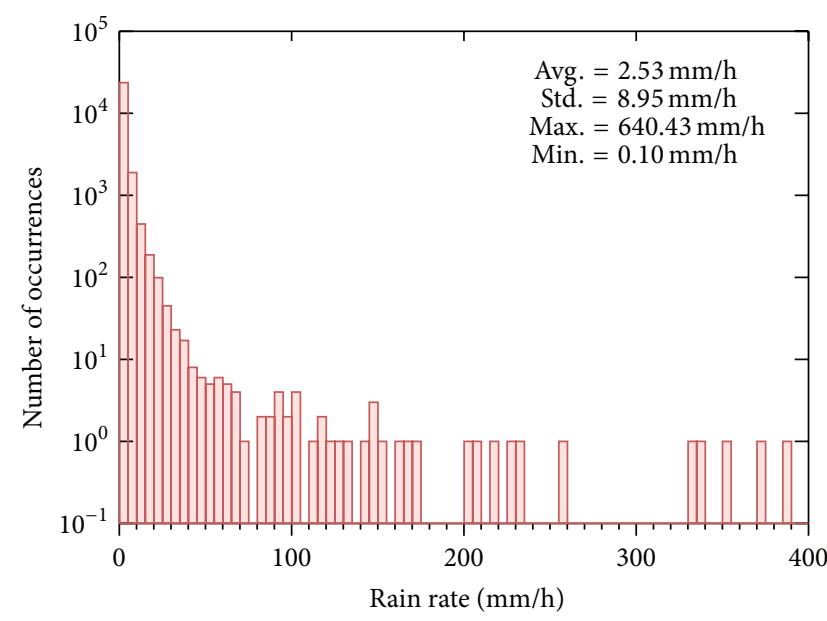

(a)

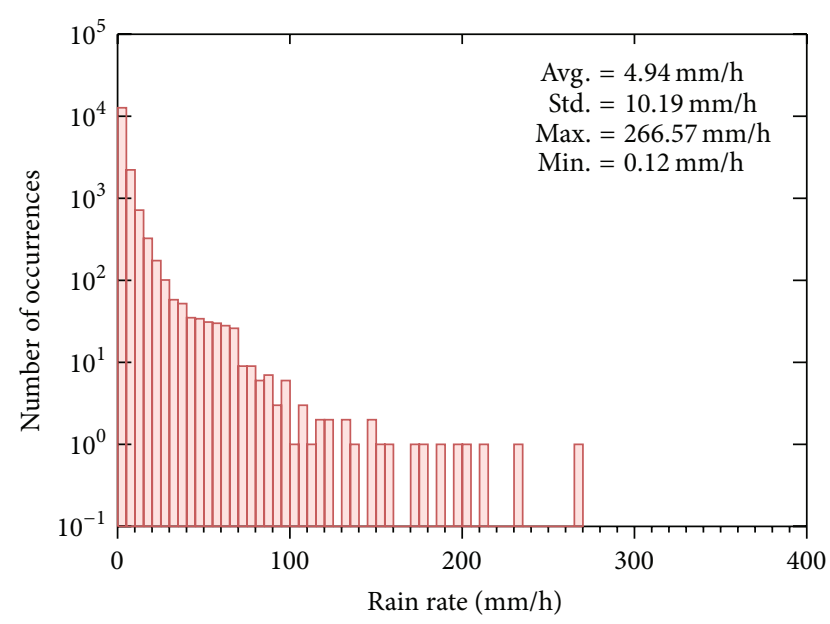

(b)

FIGURE 3: Comparison of rainfall-rate frequency obtained from the DSDs in (a) 2002 and (b) 2012.

where $\rho_{w}$ is the water density. The normalized intercept parameter $\left(N_{w}\right)$ of the gamma distribution is computed from $W$ and $D_{m}$ :

$$
N_{w}=\frac{4^{4}}{\pi \rho_{w}}\left(\frac{W}{D_{m}^{4}}\right)
$$

where $N_{w}$ is the same as the parameter $N_{0}$ of an equivalent exponential DSD. The standard deviation of $D_{m}$ is given as

$$
\sigma_{m}=\left[\frac{\int_{0}^{D_{\max }}\left(D-D_{m}\right)^{2} D^{3} N(D) d D}{\int_{0}^{D_{\max }} D^{3} N(D) d D}\right]^{1 / 2} .
$$

In the case of gamma the shape parameter $\mu$ can be derived as

$$
\frac{\sigma_{m}}{D_{m}}=\frac{1}{(4+\mu)^{1 / 2}} .
$$

Other ways to calculate $\mu$ exist, but the above form has been found to be the most stable [29].

The slope parameter $\Lambda$ can be calculated by shape and second, fourth, and sixth moments [36]:

$$
\Lambda=\left[\frac{\int_{0}^{D_{\max }} D^{2} N(D) d D \Gamma(\mu+5)}{\int_{0}^{D_{\max }} D^{4} N(D) d D \Gamma(\mu+3)}\right]^{1 / 2} .
$$

To discriminate between convective and stratiform rain, convective rain was defined as $R>5 \mathrm{~mm} \mathrm{~h}^{-1}$ and the standard deviation of rainfall rate over five consecutive samples $\left(\sigma_{R}\right)>$ $1.5 \mathrm{~mm} \mathrm{~h}^{-1}$ [26]. To analyze the characteristics of DSDs with rainfall rate, the data were categorized into four groups; $0<$ $R \leq 5 \mathrm{~mm} \mathrm{~h}^{-1}$ (Category I), $5<R \leq 10 \mathrm{~mm} \mathrm{~h}^{-1}$ (Category II), $10<R \leq 20 \mathrm{~mm} \mathrm{~h}^{-1}$ (Category III), and $R>20 \mathrm{~mm} \mathrm{~h}^{-1}$ (Category IV).

2.3. Rainfall Cases. Rainfall caused by typhoons was removed from the dataset for both years. The data used for the analysis amounted to 77 days in 2002 and 65 days in 2012. Figure 1 shows the comparison between daily rainfall measured by the disdrometer and gage for 2002 and 2012. The total rainfall measured by POSS and gage in 2002 was 1,113.5 and $1,247.0 \mathrm{~mm}$, respectively; the rainfall measured by Parsivel and gage in 2012 was $1,365 \mathrm{~mm}$ and $1290.5 \mathrm{~mm}$, respectively. The cross correlation coefficient between disdrometer and gage was 0.99 for both years, and the root mean square error was 1.73 and $1.77 \mathrm{~mm} \mathrm{~h}^{-1}$ for 2002 and 2012, respectively.

\section{Results}

3.1. Comparison of $D_{m}$. The gamma model [22] was used to determine the extent to which using disdrometers with different drop size channels affects the calculation of DSDs. The DSDs were simulated using an intercept and shapes of $8,000 \mathrm{~mm}^{-1} \mathrm{~m}^{-3}$ and $-2,0$, and 2, respectively, while the slope was incrementally increased from 0 to 6.5 in steps of 0.001 . The DSDs were generated at the same channels measured by the POSS and the Parsivel. $D_{m}$ was calculated as shown in (1) using the simulated DSDs. To match the minimum and maximum diameters of the POSS channels, drops less than $0.3 \mathrm{~mm}(\leq 0.35 \mathrm{~mm})$ and larger than $5.5 \mathrm{~mm}(\geq 5.35 \mathrm{~mm})$ were set to 0 in the Parsivel (2DVD) dataset. The average rainfall rates calculated from the simulated DSDs based on the POSS and Parsivel channel sizes were 20.3 and $20.1 \mathrm{~mm} \mathrm{~h}^{-1}$, respectively (after removing samples with a rainfall rate greater than $300 \mathrm{~mm} \mathrm{~h}^{-1}$ ). Figure 2 shows the intercomparison of $D_{m}$ using DSDs obtained from the simulation with same channels as the Parsivel and the POSS. The mean error and maximum error of $D_{m}$ between Parsivel and POSS were 0.033 0.053 and $0.143 \sim 0.156 \mathrm{~mm}$, respectively. As this difference was so small, we were able to compare DSDs from POSS and Parsivel directly and without interpolation.

3.2. Annual Variation in DSDs. The average rainfall rate observed by POSS in 2002 and Parsivel in 2012 was 2.53 and $4.94 \mathrm{~mm} \mathrm{~h}^{-1}$, respectively (Figure 3 ). The percentage 


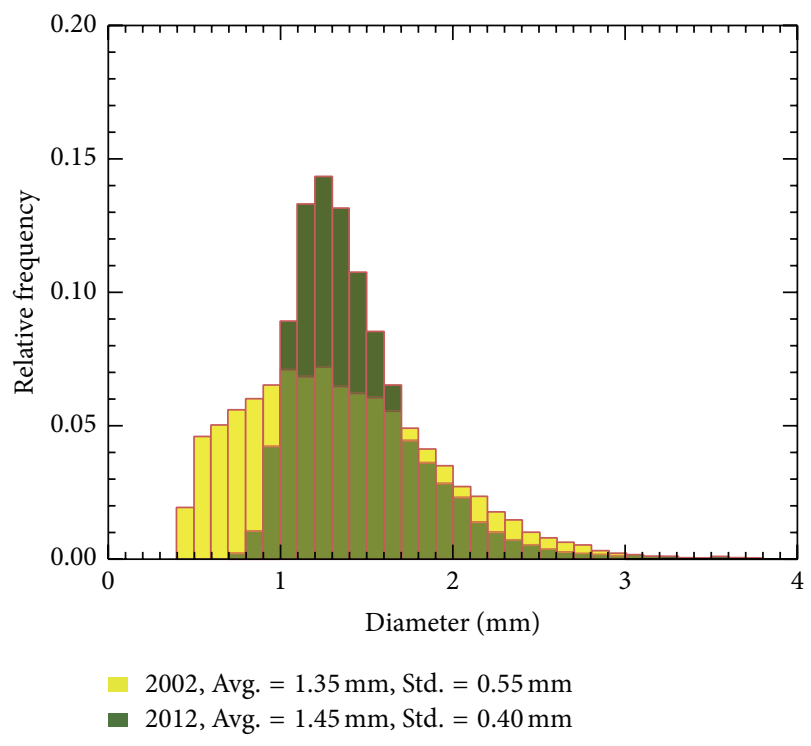

(a)

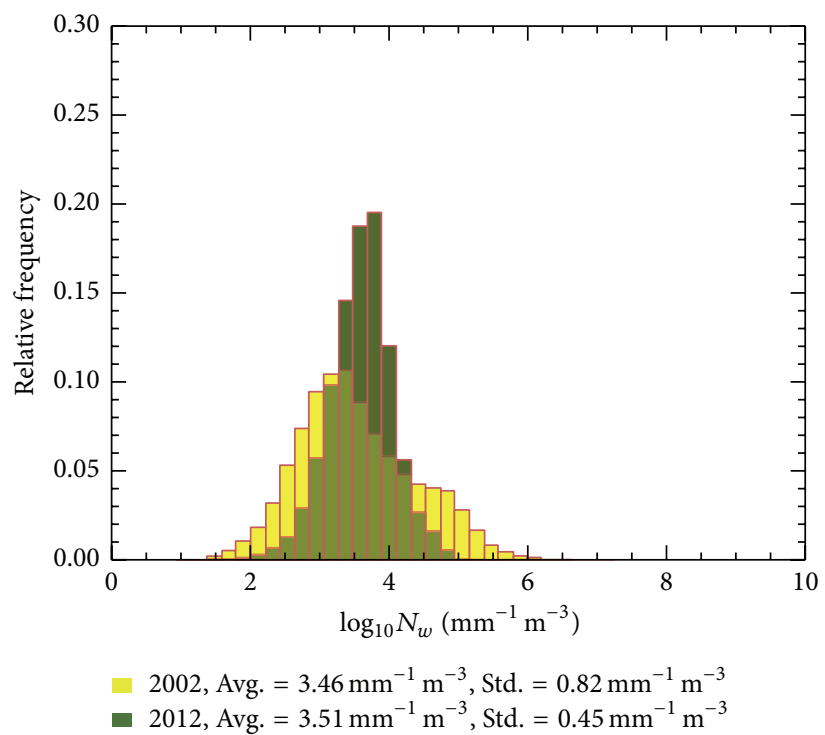

(b)

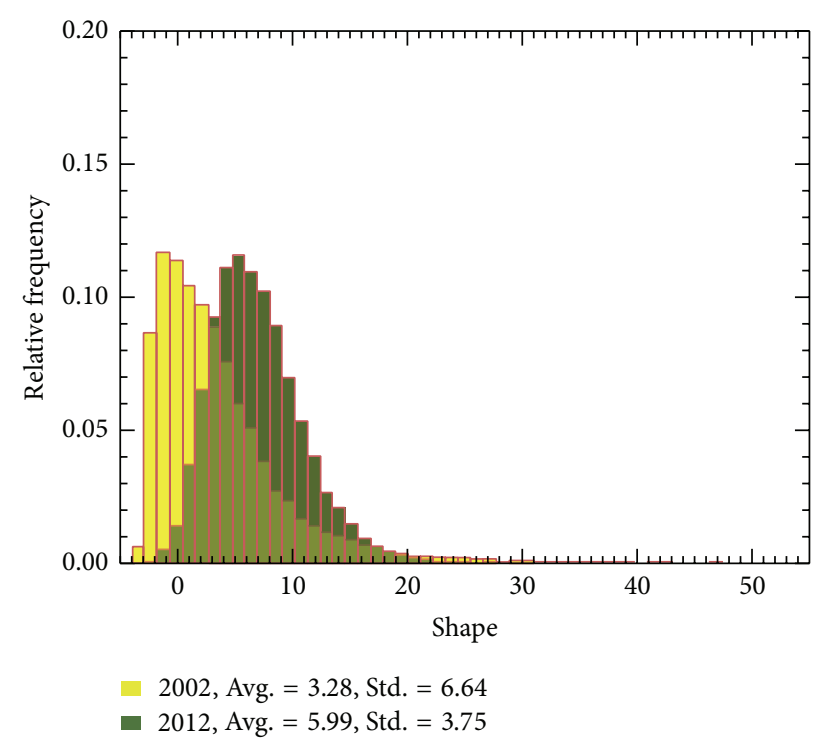

(c)

Figure 4: Comparison of (a) $D_{m}$, (b) $\log _{10} N_{w}$, and (c) shape parameter for 2002 and 2012.

occurrences of rainfall rates greater than $5 \mathrm{~mm} \mathrm{~h}^{-1}$ were $24.1 \%$ in 2012 and $10.8 \%$ in 2002 . The percentage occurrences of rainfall rates less than $5 \mathrm{~mm} \mathrm{~h}^{-1}$ in 2002 and 2012 were $89.2 \%$ and $75.9 \%$, respectively. It appears that changes in the frequency of more intense rainfall events may have contributed most to changes in the precipitation system in Busan over the 10-year period studied here.

To examine annual variations in DSDs, three parameters, $D_{m}, \log _{10} N_{w}$, and the slope, were compared for both 2002 and 2012 (Figure 4). The average $D_{m}$ and its standard deviation were 1.35 and $0.55 \mathrm{~mm}$, respectively, for 2002, and 1.45 and $0.4 \mathrm{~mm}$, respectively, for 2012. This result is slightly larger than the statistical analysis by Leinonen et al. [29] in high latitudes. From the $\log _{10} N_{w}$ histogram (Figure 4(b)), the average $\log _{10} N_{w}$ for both years appears to be similar; however, the dispersion of $\log _{10} N_{w}$ in 2002 was greater than in 2012 . Figure 4(c) shows that lower shape values dominated in 2002. This suggests that larger raindrops were the main cause of the higher rainfall rate in 2012 .

Episodes of convective and stratiform rain were classified based on the definition outlined by Bringi et al. [26]. Figure 5 shows the histogram of $D_{m}$ and $\log _{10} N_{w}$ for convective and stratiform rain in 2002 and 2012, and the proportion of convective rain in each year was $10.9 \%$ and $19.5 \%$, respectively, with concomitant occurrences of greater rates in rainfall during both years. The average $D_{m}$ and standard deviation in 2002 were slightly larger than in 2012 for both convective and stratiform rain, in contrast to $N_{w}$. The average $D_{m}$ and $\log _{10} N_{w}$ value of stratiform rain was 1.47 and $1.38 \mathrm{~mm}$, respectively, in 2002, and 3.44 and $3.48 \mathrm{~mm}^{-1} \mathrm{~m}^{-3}$, 


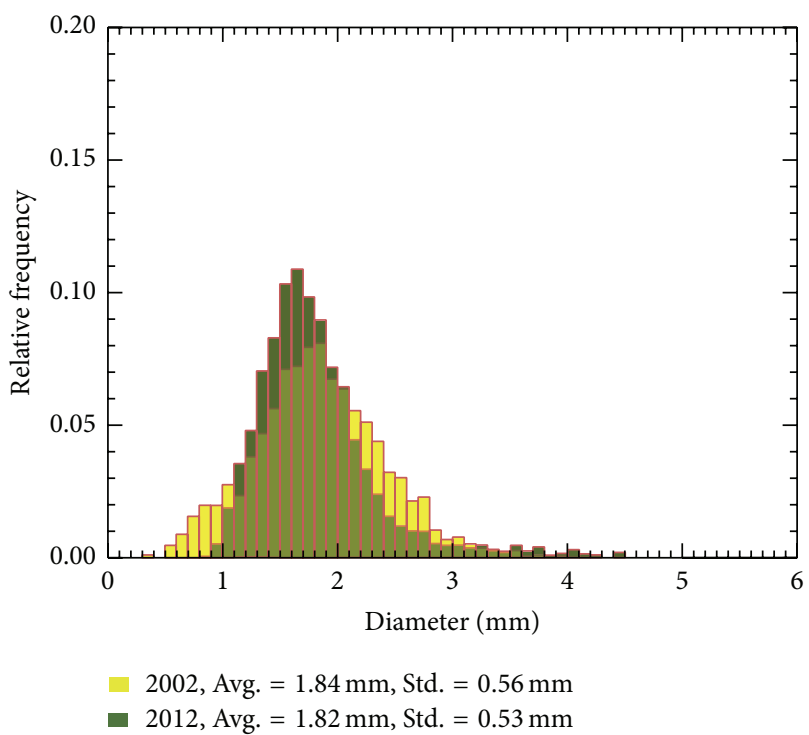

(a)

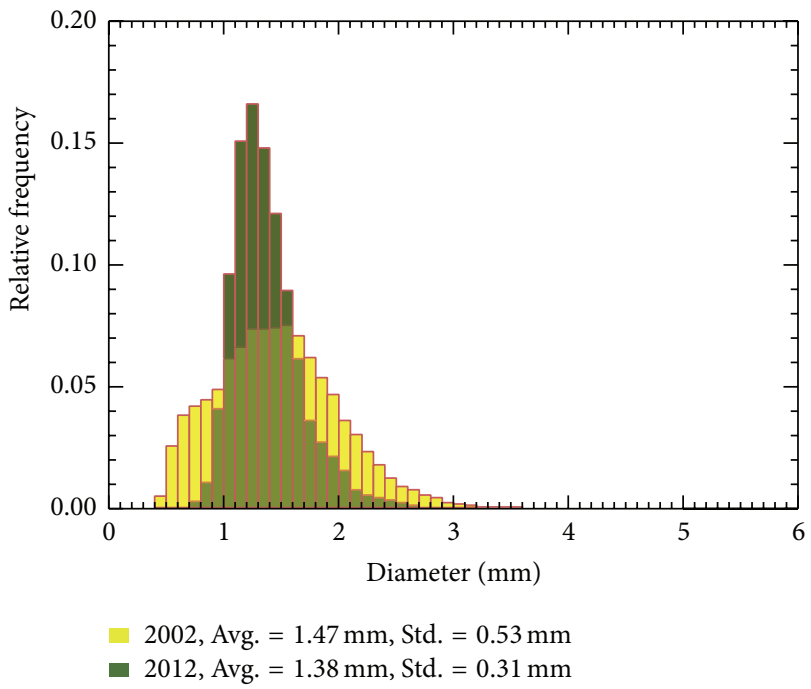

(c)

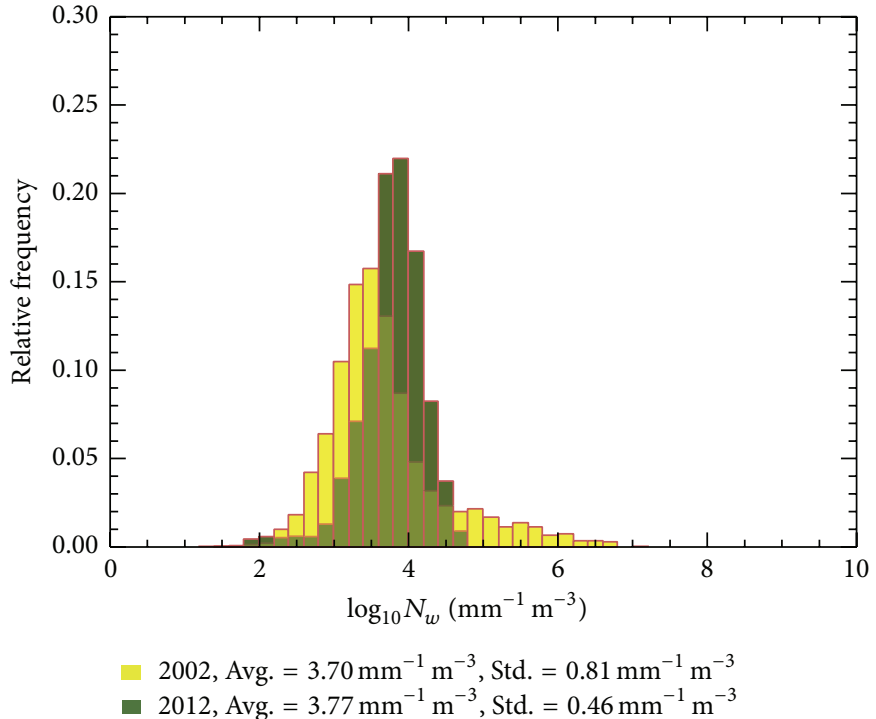

(b)

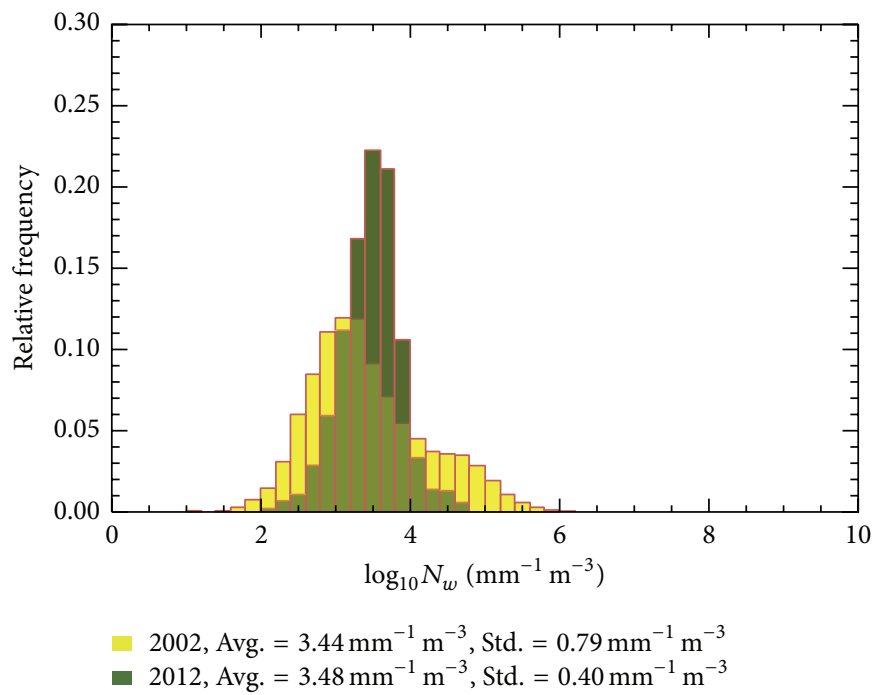

(d)

Figure 5: Histogram of $D_{m}$ and $\log _{10} N_{w}$ for convective (a and b) and stratiform rain (c and d) in 2002 and 2012.

respectively, in 2012. In comparison with the results observed by Bringi et al. [26], the averaged $D_{m}$ and $\log _{10} N_{w}$ in 2002 and 2012 were distributed in the maritime rain regime.

Whilst $D_{m}$ for all samples in 2012 was higher than for 2002, the opposite was observed for both stratiform and convective rain. This may be related to exclusion of samples during the classification of convective and stratiform rain. To examine variation in DSDs, the three parameters $\left(D_{m}\right.$, $N_{w}$, and slope) were compared in the rainfall rate categories I to IV. For categories I to IV, the sample numbers were $23574,1946,646$, and 261, respectively, in 2002, and 12600, 2299, 1055, and 637, respectively, in 2012. Higher intensity rainfall events became more frequent during the 10-year period under study. Values of $D_{m}$ for categories I and IV were larger in 2012 than in 2002; however, $D_{m}$ for categories II and III was larger in 2002. The average $D_{m}$ values for categories I to IV were $1.29,1.78,1.96$, and $1.92 \mathrm{~mm}$, respectively, in 2002, and $1.36,1.63,1.79$, and $2.18 \mathrm{~mm}$, respectively, in 2012. The average values of $\log _{10} N_{w}$ and slope are shown in Table 1.

3.3. Monthly and Hourly Variation in DSDs. To understand monthly variation in DSDs during 2002 and 2012, DSDs were recalculated by month. The data for July 2012 were not available for this study. Figure 6 shows a scatter plot of averaged $D_{m}$ and $\log _{10} N_{w}$ for each month in 2002 and 2012. During the spring and autumn seasons, there were no major differences in $D_{m}$ and $\log _{10} N_{w}$ between 2002 and 2012. The largest difference in $D_{m}$ and $\log _{10} N_{w}$ between the two years occurred in June, August, and December. During the summer season, average $D_{m}$ increased in 2012, but $\log _{10} N_{w}$ decreased in 2012. In December, $\log _{10} N_{w}$ showed very little change, 
TABLE 1: Comparison between $D_{m}, N_{w}, \mu$, and sample number for each rainfall rate category during 2002 and 2012.

\begin{tabular}{|c|c|c|c|c|c|c|c|c|}
\hline \multirow{2}{*}{ Category } & \multicolumn{4}{|c|}{2002} & \multicolumn{4}{|c|}{2012} \\
\hline & $D_{m}(\mathrm{~mm})$ & $\log _{10} N_{w}\left(\mathrm{~mm}^{-1} \mathrm{~m}^{-3}\right)$ & $\mu$ & Num. & $D_{m}(\mathrm{~mm})$ & $\log _{10} N_{w}\left(\mathrm{~mm}^{-1} \mathrm{~m}^{-3}\right)$ & $\mu$ & Num. \\
\hline $0-5 \mathrm{~mm} \mathrm{~h}^{-1}$ & 1.29 & 3.44 & 3.36 & 23,574 & 1.36 & 3.43 & 6.13 & 12,600 \\
\hline $5-10 \mathrm{~mm} \mathrm{~h}^{-1}$ & 1.78 & 3.58 & 2.50 & 1,946 & 1.63 & 3.72 & 5.87 & 2,299 \\
\hline $10-20 \mathrm{~mm} \mathrm{~h}^{-1}$ & 1.96 & 3.61 & 4.18 & 646 & 1.79 & 3.79 & 5.89 & 1,055 \\
\hline$>20 \mathrm{~mm} \mathrm{~h}^{-1}$ & 1.92 & 4.19 & 3.37 & 261 & 2.18 & 3.84 & 5.02 & 637 \\
\hline
\end{tabular}

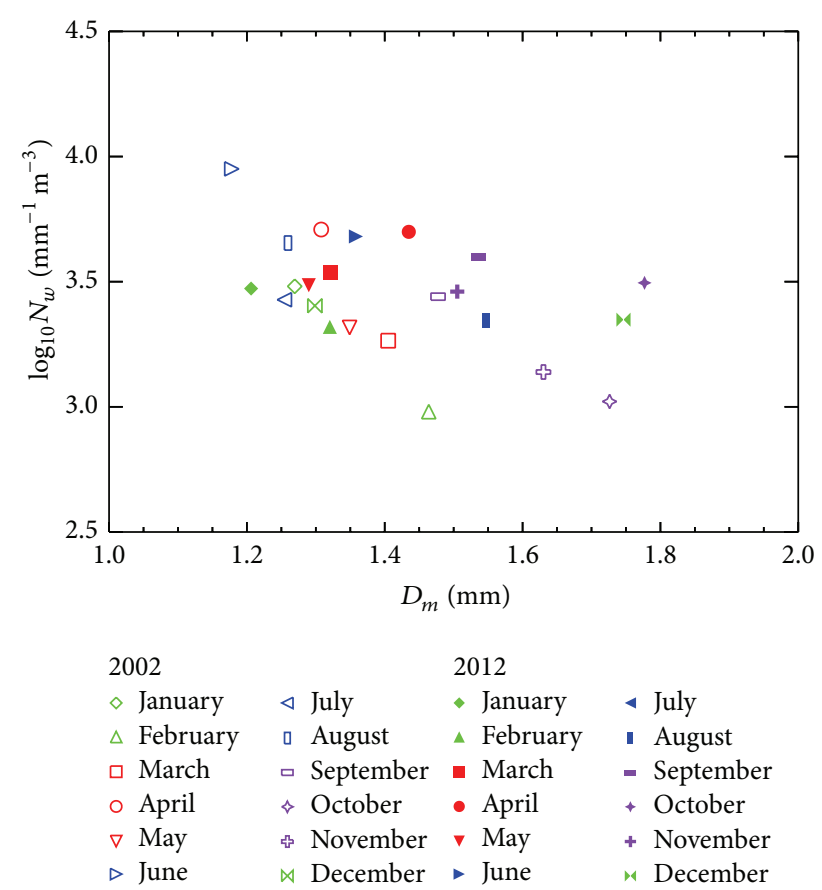

Figure 6: Scatter plots for monthly $D_{m}$ and $\log _{10} N_{w}$ in 2002 and 2012. The green symbols represent data from December, January, and February; red represents March, April, and May; blue represents June, July, and August; and purple represents September, October, and November. Open symbols indicate 2002 and solid symbols 2012.

but $D_{m}$ was much larger in 2012, suggesting that these three months contributed most to the larger $D_{m}$ observed for 2012 .

Figure 7 shows the time series of average rainfall rate, $D_{m}$, and normalized number concentration for 2002 and 2012. The peak rainfall rate in 2002 occurred in the morning, and the highest rainfall rate of $4.2 \mathrm{~mm} \mathrm{~h}^{-1}$ in 2002 appeared between 0200 and 0300 local time (LT). Peak rainfall rates in 2012 occurred in the morning and midafternoon. The average rainfall rate for 2012 was much higher than that for 2002, and $D_{m}$ in 2012 was much higher than in 2002 for almost every time period. The largest $D_{m}$ was $1.48 \mathrm{~mm}$, which occurred between 6 and 7 AM in 2002. In 2012, the peak of $D_{m}$ was $1.69 \mathrm{~mm}$, which occurred between 6 and 7 AM. Frequent episodes of heavy rainfall occurred in the morning during 2012 and were associated with larger raindrops; however, relatively smaller raindrops dominated during the afternoons. Values of $\log _{10} N_{w}$ were comparable in 2002 and 2012.

\section{Summary and Concluding Remarks}

To investigate the variation in DSDs obtained by POSS and Parsivel disdrometers during the years 2002 and 2012 in Busan, Korea, annual, monthly, and hourly distributions of three parameters $\left(D_{m}, N_{w}\right.$, and shape) were calculated using a normalized gamma model.

To determine whether substantial differences exist between $D_{m}$ calculated using POSS and Parsivel, which have different bin sizes, DSDs were simulated using the gamma model and compared. The maximum difference of $D_{m}$ between both disdrometers was $0.143 \sim 0.156 \mathrm{~mm}$, and the average difference was $0.033 \sim 0.053 \mathrm{~mm}$; as this difference was so small, we were able to compare DSDs from POSS and Parsivel directly and without interpolation.

The annually averaged rainfall rate increased during the course of this study in Busan. Classification of convective and stratiform rain was performed using the method proposed by Bringi et al. [26]. Convective rain occurred more frequently in 2012 compared with 2002 . The $D_{m}$ of convective and stratiform rain was higher in 2002 than in 2012. Concordantly, the distribution of $N_{w}$ exhibited an inverse trend. The frequency of rainfall rates greater than $20 \mathrm{~mm} \mathrm{~h}^{-1}$ also increased and were associated with larger $D_{m}$ in 2012. The $D_{m}$ associated with medium $\left(5<R<10 \mathrm{~mm} \mathrm{~h}^{-1}\right)$ and strong $(10<R<$ $20 \mathrm{~mm} \mathrm{~h}^{-1}$ ) rainfall rate categories were greater in 2002 than in 2012 .

Monthly variation in DSDs was also investigated during this study. The increase in $D_{m}$ over other months for July, August, and December was more marked in 2012 than in 2002. In spring and autumn, there were no substantial changes in $D_{m}$ and $N_{w}$ between 2002 and 2012. Peak rates of rainfall in 2002 occurred in the morning, and the highest observed rainfall rate $\left(4.2 \mathrm{~mm} \mathrm{~h}^{-1}\right)$ occurred between 0200 and $0300 \mathrm{LT}$. In contrast, peak rates of rainfall occurred in both the morning and the afternoon in 2012. $D_{m}$ was much higher than that in 2002 in almost every time period. Larger raindrops contributed to the high rate of rainfall that occurred in the mornings, but relatively smaller raindrops dominated in the afternoon during 2012.

These results suggest that the increase in raindrop size that has been observed in Busan may continue in the future; however, more research will be required if we are to fully understand this phenomenon. Rainfall variables are highly dependent on drop size and so should be recalculated using the newest DSDs to allow more accurate polarimetric radar rainfall estimation. 


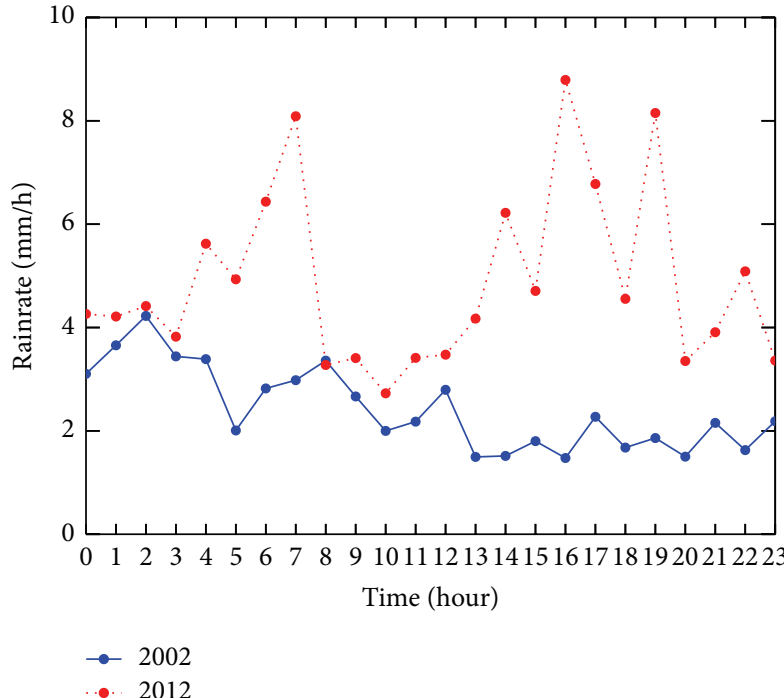

(a)

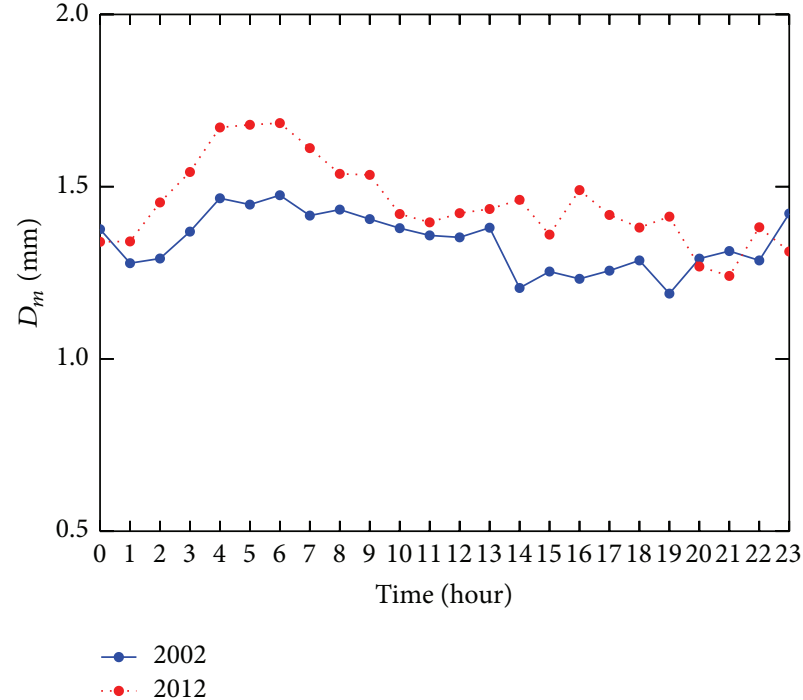

(b)

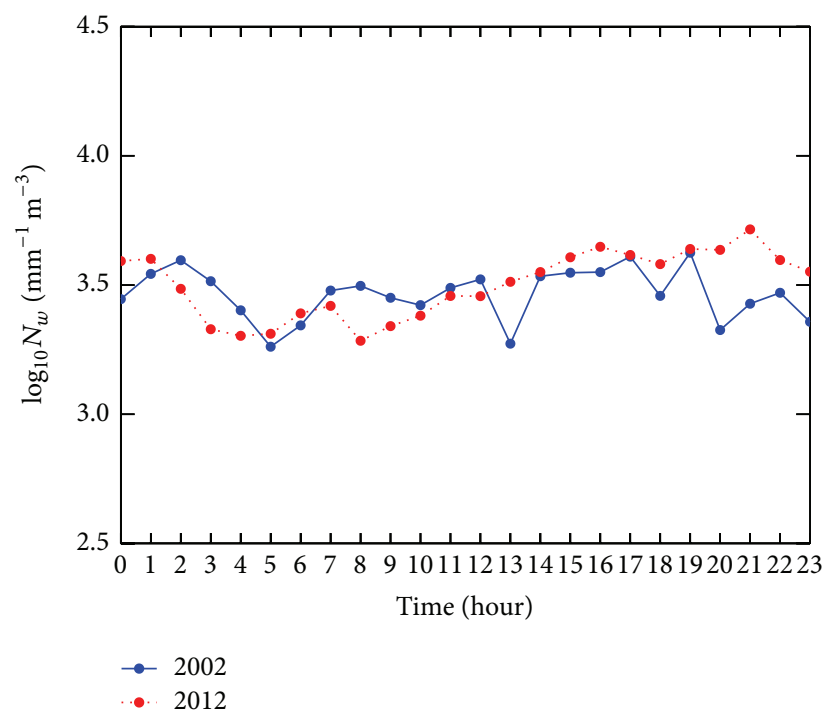

(c)

Figure 7: Time series of averaged (a) rainfall rate, (b) $D_{m}$, and (c) $\log _{10} N_{w}$ in 2002 and 2012.

\section{Conflict of Interests}

The authors declare that they have no conflict of interests regarding the publication of this paper.

\section{Acknowledgments}

This research was supported by the National Research Foundation of Korea (NRF) through a grant provided by the Korean Ministry of Education, Science \& Technology (MEST) in 2014 (no. K200603874). This work was also funded by the Korea Meteorological Administration Research and Development Program under Grant CATER 2012-2071.

\section{References}

[1] A. R. Jameson and A. B. Kostinski, "What is a raindrop size distribution?" Bulletin of the American Meteorological Society, vol. 82, no. 6, pp. 1169-1177, 2001.

[2] R. Uijlenhoet and D. Sempere Torres, "Measurement and parameterization of rainfall microstructure," Journal of Hydrology, vol. 328, no. 1-2, pp. 1-7, 2005.

[3] E. Campos and I. Zawadzki, "Instrumental uncertainties in ZR relations," Journal of Applied Meteorology, vol. 39, no. 7, pp. 1088-1102, 2000.

[4] C. H. You, D. I. Lee, S. M. Jang et al., "Characteristics of rainfall systems accompanied with Changma front at Chujado in Korea," Asia-Pacific Journal of Atmospheric Sciences, vol. 46, no. 1, pp. 41-51, 2010. 
[5] J. O. Laws and D. A. Parsons, "The relation of rain-size to intensity," Transactions American Geophysical Union, vol. 24, pp. 432460, 1943.

[6] J. S. Marshall and W. M. K. Palmer, "The distribution of raindrops with size," Journal of Meteorology, vol. 5, no. 4, pp. 165$166,1948$.

[7] J. Joss and A. Walvogel, "A spectrograph for automatic measurement of rainfall," Geofisica Pura e Applicata, vol. 68, pp. 240246, 1967.

[8] B. E. Sheppard, "Measurement of raindrop size distributions using a small Doppler radar," Journal of Atmospheric and Oceanic Technology, vol. 7, no. 2, pp. 255-268, 1990.

[9] M. Löffler-Mang and J. Joss, "An optical disdrometer for measuring size and velocity of hydrometeors," Journal of Atmospheric and Oceanic Technology, vol. 17, no. 2, pp. 130-139, 2000.

[10] M. Schönhuber, G. Lammer, and W. L. Randeu, "The 2Dvideo-distrometer," in Precipitation: Advances in Measurement, Estimation and Prediction, pp. 3-31, Springer, Berlin, Germany, 2008.

[11] J. Jaffrain and A. Berne, "Experimental quantification of the sampling uncertainty associated with measurements from Parsivel disdrometers," Journal of Hydrometeorology, vol. 12, no. 3, pp. 352-370, 2011.

[12] B. E. Sheppard and P. I. Joe, "Comparison of raindrop size distribution measurements by a Joss-Waldvogel disdrometer, a PMS 2DG spectrometer, and a POSS Doppler radar," Journal of Atmospheric \& Oceanic Technology, vol. 11, no. 4, pp. 874-887, 1994.

[13] B. E. Sheppard, "Sampling errors in the measurement of rainfall parameters using the precipitation occurence sensor system (POSS)," Journal of Atmospheric and Oceanic Technology, vol. 24, no. 2, pp. 125-140, 2007.

[14] A. Tokay, A. Kruger, and W. F. Krajewski, "Comparison of drop size distribution measurements by impact and optical disdrometers," Journal of Applied Meteorology, vol. 40, no. 11, pp. 2083-2097, 2001.

[15] M. Thurai, W. A. Petersen, A. Tokay, C. Schultz, and P. Gatlin, "Drop size distribution comparisons between Parsivel and 2-D video disdrometers," Advances in Geosciences, vol. 30, pp. 3-9, 2011.

[16] A. Tokay, W. A. Petersen, P. Gatlin, and M. Wingo, "Comparison of raindrop size distribution measurements by collocated disdrometers," Journal of Atmospheric and Oceanic Technology, vol. 30, no. 8, pp. 1672-1690, 2013.

[17] W. F. Krajewski, A. Kruger, C. Caracciolo et al., "DEVEXdisdrometer evaluation experiment: basic results and implications for hydrologic studies," Advances in Water Resources, vol. 29, no. 2, pp. 311-325, 2006.

[18] C.-H. You, D.-I. Lee, M. Jang, K.-J. Seo, K.-E. Kim, and B.-S. Kim, "The characteristics of rain drop size distributions using a POSS in Busan area," Journal of the Korean Meteorological Society, vol. 40, pp. 713-724, 2004.

[19] C.-H. You, D.-I. Lee, M. Jang, H.-K. Kim, J.-H. Kim, and K.-E. Kim, "Variation of rainrate and radar reflectivity in Busan area and its measurement by cloud types," Journal of the Korean Meteorological Society, vol. 41, pp. 191-200, 2005.

[20] C.-H. You, M.-Y. Kang, D.-I. Lee, and H. Uyeda, "Rainfall estimation by S-band polarimetric radar in Korea. Part I: preprocessing and preliminary results," Meteorological Applications, vol. 21, no. 4, pp. 975-983, 2014.

[21] C. H. You, D. I. Lee, and M. Y. Kang, "Rainfall estimation using specific differential phase for the first operational polarimetric radar in Korea," Advances in Meteorology, vol. 2014, Article ID 413717, 10 pages, 2014.

[22] C. W. Ulbrich, "Natural variations in the analytical form of the raindrop size distribution.," Journal of Climate \& Applied Meteorology, vol. 22, no. 10, pp. 1764-1775, 1983.

[23] P. T. Willis, "Functional fits to some observed drop size distributions and parameterization of rain," Journal of the Atmospheric Sciences, vol. 41, no. 9, pp. 1648-1661, 1984.

[24] J. Testud, S. Oury, R. A. Black, P. Amayenc, and X. Dou, "The concept of 'normalized' distribution to describe raindrop spectra: a tool for cloud physics and cloud remote sensing," Journal of Applied Meteorology, vol. 40, no. 6, pp. 1118-1140, 2001.

[25] A. J. Illingworth and T. M. Blackman, "The need to represent raindrop size spectra as normalized gamma distributions for the interpretation of polarization radar observations," Journal of Applied Meteorology, vol. 41, no. 3, pp. 286-297, 2002.

[26] V. N. Bringi, V. Chandrasekar, J. Hubbert, E. Gorgucci, W. L. Randeu, and M. Schoenhuber, "Raindrop size distribution in different climatic regimes from disdrometer and dual-polarized radar analysis," Journal of the Atmospheric Sciences, vol. 60, no. 2, pp. 354-365, 2003.

[27] T. Islam, M. A. Rico-Ramirez, M. Thurai, and D. Han, "Characteristics of raindrop spectra as normalized gamma distribution from a Joss-Waldvogel disdrometer," Atmospheric Research, vol. 108, pp. 57-73, 2012.

[28] M. Montopoli, F. S. Marzano, and G. Vulpiani, "Analysis and synthesis of raindrop size distribution time series from disdrometer data," IEEE Transactions on Geoscience and Remote Sensing, vol. 46, no. 2, pp. 466-478, 2008.

[29] J. Leinonen, D. Moisseev, M. Leskinen, and W. A. Petersen, "A climatology of disdrometer measurements of rainfall in finland over five years with implications for global radar observations," Journal of Applied Meteorology and Climatology, vol. 51, no. 2, pp. 392-404, 2012.

[30] C. W. Ulbrich and D. Atlas, "Microphysics of raindrop size spectra: tropical continental and maritime storms," Journal of Applied Meteorology and Climatology, vol. 46, no. 11, pp. 17771791, 2007.

[31] A. Tokay and D. A. Short, "Evidence from tropical raindrop spectra of the origin of rain from stratiform versus convective clouds," Journal of Applied Meteorology, vol. 35, no. 3, pp. 355371, 1996.

[32] R. S. Tenório, M. C. D. S. Moraes, and H. Sauvageot, "Raindrop size distribution and radar parameters in coastal tropical rain systems of northeastern Brazil," Journal of Applied Meteorology and Climatology, vol. 51, no. 11, pp. 1960-1970, 2012.

[33] I. Zawadzki and A. M. Agostinho, "Equilibrium raindrop size distributions in tropical rain," Journal of the Atmospheric Sciences, vol. 45, pp. 3452-3459, 1988.

[34] L. S. Kumar, Y. H. Lee, and J. T. Ong, “Two-parameter gamma drop size distribution models for singapore," IEEE Transactions on Geoscience and Remote Sensing, vol. 49, no. 9, pp. 3371-3380, 2011.

[35] T. Kozu, T. Shimomai, Z. Akramin, Y. Marzuki, Y. Shibagaki, and H. Hashiguchi, "Intraseasonal variation of raindrop size distribution at Koto Tabang, West Sumatra, Indonesia," Geophysical Research Letters, vol. 32, no. 7, pp. 1-5, 2005.

[36] G. Zhang, J. Vivekanandan, E. A. Brandes, R. Meneghini, and T. $\mathrm{Kozu}$, "The shape-slope relation in observed gamma raindrop size distributions: statistical error or useful information," Journal of Atmospheric and Oceanic Technology, vol. 20, no. 8, pp. 1106-1119, 2003. 

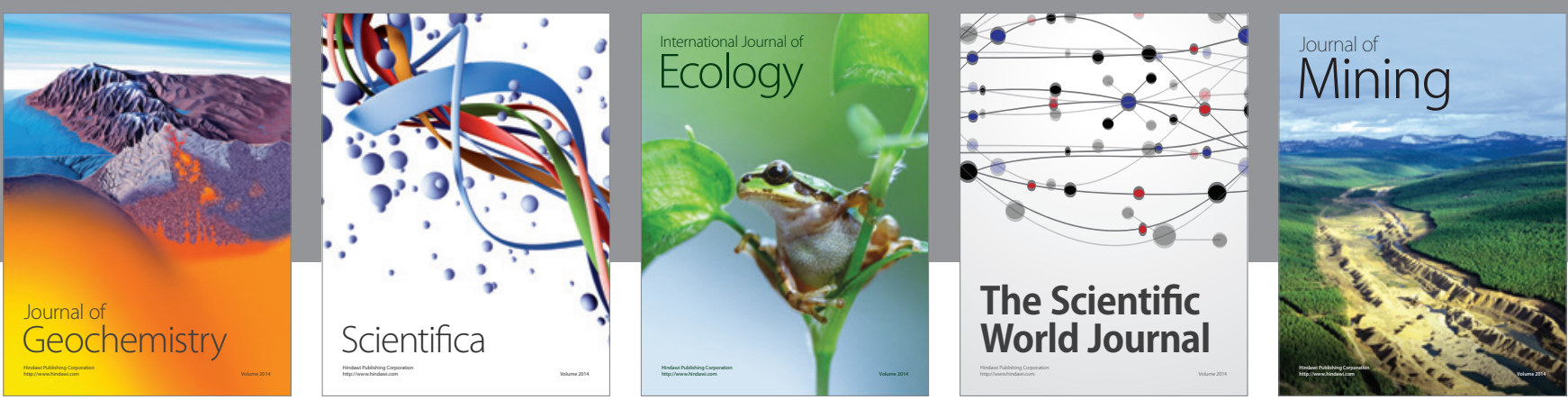

The Scientific World Journal
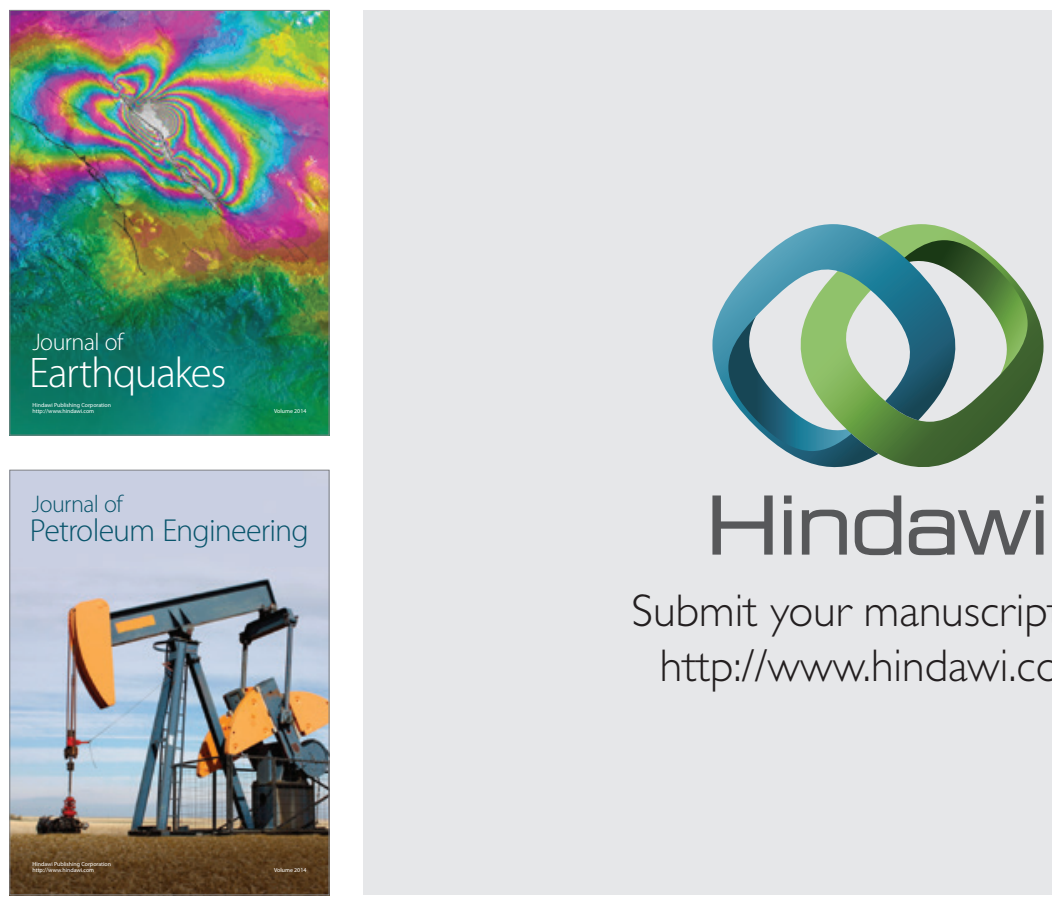

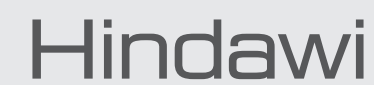

Submit your manuscripts at

http://www.hindawi.com
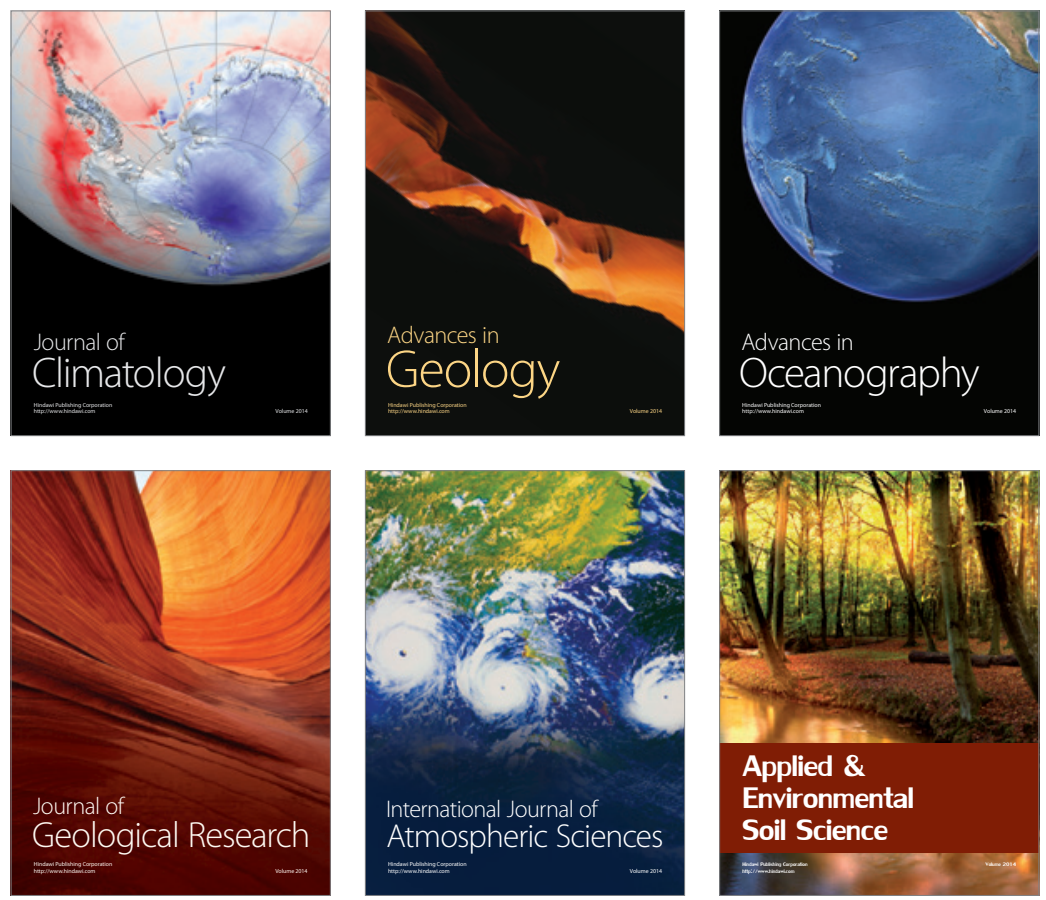
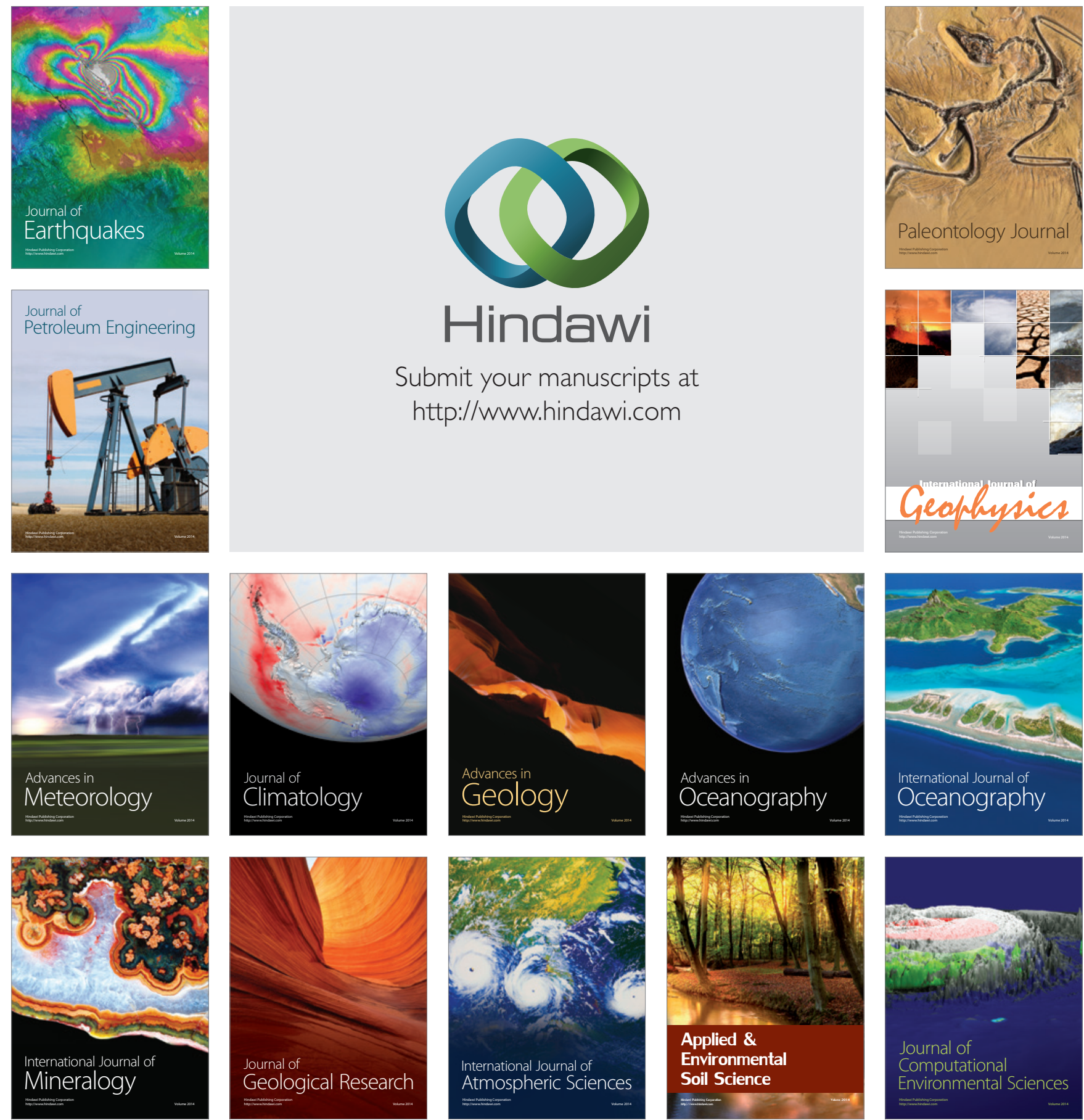